\title{
A Web-based Instrument to Initialize Learning Style: An Interactive Questionnaire Instrument
}

\author{
https://doi.org/10.3991/ijet.v13i12.8725 \\ Doniyorbek Qambaralievich Ahmadaliev( $\left.{ }^{\varpi}\right)$, Chen Xiaohui \\ Northeast Normal University, Changchun, China \\ duon 1124 @ nenu. edu.cn \\ Murodjon Abduvohidov \\ Andijan State University, Andijan, Uzbekistan
}

\begin{abstract}
Being able to detect and address individual learners' learning preferences can be a basis for effective learning and teaching. Many researches are contributing to define the potential differences of individual preferences in learning. In this paper, we present an interactive Web-based instrument to initiate student's learning style. The instrument uses learner's interaction with learning objects as hint and representing them as the student's learning style. By applying the instrument, we have been able to detect initial learning styles accurately. Evaluation of our experimental results showed high precision. Besides, very high satisfactory feedbacks were received from students. Based on the mentioned benefits and study results, our method has potential influence on defining individual's preference in learning.
\end{abstract}

Keywords-Learning style detection, learning preferences, Web-based instrument, learning objects.

\section{Introduction}

Everyone's learning capacity is largely determined by the level of their conscious attention to their sense. With the respect to the idea that everyone is capable of learning, there many researches are contributing to define the potential differences of individual preferences in learning. There is a strong believe that educators and course designers must take the students' learning styles in to account. Strong theoretical evidences derived from research in brain functioning and psychology supports the idea that, the learning style of an individual can be defined accurately and measured reliably [1]. So, the way of learning is vary-by seeing and hearing; reflecting and acting; reasoning logically and intuitively; memorizing and visualizing; so on [2]. A student's progress in learning depends on, to some degree, his/her background knowledge in the subject being taught and personal ability to gain information. Besides, student's learning style also have potential impact on his/her progress.

Learning style models are being used in many educational settings in a form of questionnaire to identify students' individual learning preferences. But, a contradictory idea 
is still being ignored that traditional surveying method like questionnaire in the current field is time consuming for students and error prone for data collection [3-5].

In this study we implemented an interactive Web based instrument for identifying user's learning style. The aim of this instrument is to replace traditional questionnaire and face to face interview to interactive and computer based approach to determine a learner's learning style.

The rest of the paper is organized as follows: A brief overview on related works are presented in the Section 2. The Section 3 describes the learning styles. Section 4 consists of introduction to proposed work. We describe the methodology for this study in Section 5. Then we summarize the results and discussion in Sections 6. Finally, we conclude in section 7 .

\section{Related works}

Several studies are already carried out which use various automated ways of identifying learning style. [4] proposed a genetic algorithm approach for automatically identifying and tracking students' learning styles over time based on the actions he/she made while attending different academic courses. Furthermore, automatic detecting of learning style employs comprehensive AI algorithms to enhance e-learning systems. [6] evaluates Bayesian networks at detecting the learning style of a student in a Web-based education system. Florián represents the difference of Felder's learning styles by using random variables and the factors of each dimension are extracted from the users' interactions with the system. By capturing the learner's behavior on a web portal, [7] applies Web-log mining method to identify students' learning styles. Also, [8] have concentrated on the literature-based approach with respect to FSLSM. Dung's approach is the most related work to our study, promotes a new method to estimate each student's learning styles based on the number of visits and the time that he/she spent on learning objects.

The only disadvantage of the aforementioned works is that their system identifies students' preference during the class hours, the investigation gives the result gradually, maybe in the middle of the semester or in the end. Furthermore, most of the systems follow similar patterns[9]. To the best of our knowledge, in automatic methods, initializing the students' learning style in the beginning of the sessions is still lucking. In this study, we propose an interactive Web-based instrument which can be run once for a short time in the beginning of the course. We followed the Felder's ILS theory to design learning objects for the context of the instrument.

\section{$3 \quad$ Learning styles}

There are many competitive definitions for learning style, but the definition given in [10] is widely used, which states that: a learning style is the composite of characteristic cognitive, effective, and psychological factors that serve as relatively stable indicators of how a learner perceives, interacts with, and responds to the learning environment. In 
the field of learning style, various models exist and they have different theoretical orientations towards different disciplines. Furthermore, as [1] reports there are more than 70 worthy learning style models available. Among these models, Felder-Silverman Learning Style Model (FSLSM) [2] is the most frequently being used in engineering education related studies.

In this study, we focus on the FSLSM for reasons of its widely usage in several majors and its nature for covering engineering education. Originally, FSLSM addresses the following three problems [2]:

- Which aspects of learning style are particularly significant in engineering education?

- Which learning styles are preferred by most students and which are favored by the teaching styles of most professors?

- What can be done to reach students whose learning styles are not addressed by standard methods of engineering education?

FSLSM distinguishes learners with values on four dimensions - sensing/intuitive, visual/verbal, active/reflective, and sequential/global. Dimensions in this model are not original, they are from the other most valuable models. For instance, the first dimension - sensing/intuition - in FSLSM reflects the one of the four dimensions in[11], and active/reflective dimension is analogous to the respective dimension in [12]. The following paragraphs give brief definitions for each dimension:

The sensing/intuitive - two ways in which a learner perceives the world. Learners with sensing perception prefer concrete information, intuitive learners on the other hand, tend to prefer abstraction. Sensors like facts, data, and real world experimentation; initiators prefer interpretations, theories and models.

The visual/verbal dimension corresponds with the ways learners receive information. Visual learners are believed to be the best in learning visual information - pictures, diagrams, symbols; verbal learners remember much in the way of spoken or written words. Written words should not be confused with the scale of visual, since our brain generally convert written words into their spoken equivalents and process them in the same way that they process spoken words [13].

The dimension of sequential/global scales learners in the way of how they understand the content. Sequential learners get information in linear and emphasize to details; global learners are holistic thinkers and tend to get big picture of the subject. Learners with sequential preference like to get information step-by-step, and they learn best when the learning material is given progresses steadily. Global learners tend to understand more efficiently when they are presented overall structure and they are not patient with much details.

The active/reflective - this dimension represents the way of processing the information. Active learners learn best in an active learning environment which provides working with group and let them try things out. Reflective learners, on the other hand, like to think first before taking an action and prefer to study more details. 


\section{$4 \quad$ Proposed instrument}

When we were teaching engineering students for algorithms there was a need for initial information about students' learning style. The existing literature suggests many reasonable methods to collect information on students' learning style. To the best of our knowledge, there was a lack for an application which provides an interactive way of initializing learning style. Therefor we have built a Web-based interactive instrument. We have re-used a number of open source web frameworks to control and track user interaction with the system.

The web framework libraries we have developed utilize the instrument with a number of key functionalities. A part of the library is responsible to track the users' interaction with the instrument and take the hints, the other one is to measure the students learning style by using a simple rule-based method with the data collected from the hints. Every action the student has made is taken as a hint. A hint is the interaction of a student with a learning object presented to him/her on a web page. Each learning object and knowledge components were designed to represent at least one of the factors of eight factor solution. These factors are the eight factor solution for the ILS like in (Table 1) [14]. The instrument distinguishes students' leaning style in four dimensions. For every dimension, instructors have designed relevant content materials and tests based on each factors.

When we refer a learning object in this paper, we mean a collection of contents or practice items covering one or more knowledge components. Knowledge components other common terms are like concepts, skills, principles or schemata - are introduced.

Learning objects used in this instrument were retrieved from the pre-designed course syllabus of target institution. The course taken for this study was Introduction to Algorithms. For every dimension there are five variances of learning objects. In total twenty items were extracted from the learning objects. (Table 1) presents the number of items for each dimension and description of the factors.

Table 1. Factors for eight factor solution

\begin{tabular}{|c|c|c|c|}
\hline $\begin{array}{l}\text { Dimen- } \\
\text { sions }\end{array}$ & Scale & $\begin{array}{l}\text { Number of } \\
\text { items for } \\
\text { each factor }\end{array}$ & Factors \\
\hline Perception & $\begin{array}{l}\text { Sensing/ } \\
\text { Intuitive }\end{array}$ & 5 & $\begin{array}{l}\text { Preference for concrete information (facts, data, the "real } \\
\text { world") or abstraction (interpretations, theories, models) }\end{array}$ \\
\hline \multirow{2}{*}{ Input } & \multirow{2}{*}{$\begin{array}{l}\text { Visual/ } \\
\text { Verbal }\end{array}$} & \multirow{2}{*}{5} & Information format preferred for input \\
\hline & & & Information format preferred for memory or recall \\
\hline \multirow{2}{*}{$\begin{array}{l}\text { Under- } \\
\text { standing }\end{array}$} & \multirow{2}{*}{$\begin{array}{l}\text { Sequential/ } \\
\text { Global }\end{array}$} & \multirow{2}{*}{5} & Linear/sequential or random/holistic thinking \\
\hline & & & Emphasize details (the trees) or the big picture (the forest) \\
\hline \multirow{3}{*}{ Processing } & \multirow{3}{*}{$\begin{array}{l}\text { Active/ } \\
\text { Reflective }\end{array}$} & \multirow{3}{*}{5} & Action-first or reflection-first \\
\hline & & & Outgoing or reserved \\
\hline & & & Favorable or unfavorable attitude toward group work \\
\hline
\end{tabular}


After a user has logged in, the Web-based instrument starts presenting learning objects in a web page. As the user continues, the system asks whether to take a relevant test based on the previous learning object presented or shows options to pick a preferred one. To detect the user's learning style, for example, a learning object about the expressing methods of an algorithm is presented and a simple problem with its two ways of solving it, say, with natural language and with flow-chart is shown. Another example for the dimension of visual/verbal is illustrated in (Figure 1, a). A learning object in this figure is illustrated in two formats, one with a diagram and the other with the same knowledge component but written explicitly with words except with some extra information injected. As the user continues, the system interrupts by asking a question based on the previous step (Figure 1, b). The option the user has picked represents as a hint for either scale of the dimension.

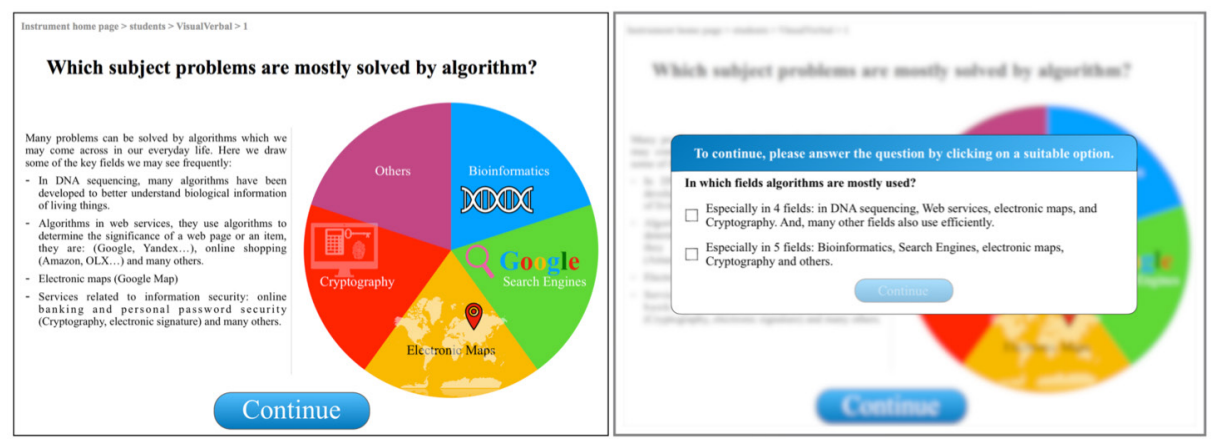

a)

b)

Fig. 1. Screenshot from Visual/Verbal relevant pattern detecting page of the instrument

In (Figure 2) the researcher is trying to determine students' intuitive/sensing preference by asking a hypothetical question and then letting students to give their opinion about this assumption.

For this assumption, students' reaction would vary, according to their learning style:

- Sensor learner's answers are usually based on facts and real data, and may say: "I cannot say something" or, if they know about it: "I confirm this assumption" or "I do not confirm this assumption".

- Intuitive learner's answer involves indirect perception and seem to be intrigued speculation and imagination, and may say: "Sure, why not ...". 
Instrument home page $>$ students $>$ SensingIntuitive $>5$

\section{If we write a sandwich-making algorithm to the computer, it would make a billion sandwiches for us in a second. What do you think on this assumption?}

It's hard to believe. Because, it depends on the speed and well equipped. A machine with

$1.2 \mathrm{GHz}$ CPU can do it, at least there were no other potential task loadings.

Yes, I can believe. Because, the computers available now can do more than that.

\section{Continue}

Fig. 2. Screenshot from Sensing/Intuitive relevant pattern detecting page of the instrument

As long as their likely perceptions are known, then their agreement for such answers are also highly expected.

\section{$5 \quad$ Methodology}

The current study was carried out in an "Introductory to algorithms" class at the information technology department of Andijan State University (Uzbekistan). Participants were $40(n=40)$ first-year undergraduate students. The Web-based instrument was designed as a threshold which can be taken once as brief opening class to initialize students' learning style. It was introduced to students on their first session of Introductory to Algorithms class.

The instrument observes the students' preference by using one of the two ways, it tracks the user interaction with the system or gives a test related to the concept or knowledge component just introduced and then the interaction behavior or test result will be taken as hint, (A prototype of the instrument can be seen at: http://anketa.murodjon.uz). Unlike the other electronic version of individual's preference measuring methods, it was designed as an online introduction material embedded with tests and activity tracking mechanism. The experiment can be conducted before a course subject starts or in the beginning of courses. At the end of the experiment, the web instrument asked students to leave their feedbacks whether showing their agreement or disagreement to the accuracy of the instrument. The data, measured as learning style of the given student and the feedback on that result, will be saved on to the server. The information can be used as an initial reference for teachers and instructors. 


\section{Results and discussion}

On this experiment we have established that from one hand, students' learning styles can be initialized ahead of the class sessions, and also the experiment has shown a promising accurate results on students' preferences.

The instrument defines learning styles by using scales from +5 to -5 for each dimension (including only odd values). Then, the learning style for each learner is characterized by four values, ranging from +5 to -5 for every dimension. Values are labeled as either scale of a dimension (for example, active or reflective) if they are equal to either extreme $( \pm 3, \pm 5)$. If the values are equal to $( \pm 1)$, they are labeled as natural.

In order to evaluate the precision of our method, we compared the results of the proposed web-based instrument against to the ILS questionnaire proposed by [15]. Students who have participated in this experiment they were also asked to take the ILS questionnaire. The following equation (1) is measuring the results for precision, we used the method proposed by [5].

$$
\text { Precision }=\frac{\sum_{1}^{n=40} \operatorname{Sim}\left(L S_{\text {determined }}, L S_{I L S}\right)}{n}
$$

where

$L S_{\text {determined }}$ is the defined value of learning style measured by our method, LSILS is the defined value of learning style of ILS questionnaire,

Sim equals to 1 if $L S_{\text {determined }}$ and $L S I L S$ match, 0.5 if at-least one of their value is neutral and the other is an extreme value, and 0 if they do not match.

Precision results and the percentage of agreed students based on their feedback are depicted in (Table 2). As we have seen the degrees of precision to dimensions sensing/intuitive, active/reflective, and sequential/global are relatively high (above than $70 \%$ ), for the dimension of visual/verbal is also satisfied (62.5\%). Besides, students' feedback for the results of the proposed instrument is high. 88 percent of students indicated that, results are similar to their preferences for all dimension of learning styles.

Table 2. Precision results by comparison of the proposed instrument and ILS questionnaire

\begin{tabular}{|l|c|c|c|c|c|}
\hline & Sensing/Intuitive & Visual/Verbal & Sequential/Global & Active/Reflective & $\begin{array}{c}\text { Student } \\
\text { satisfaction }\end{array}$ \\
\hline Precision (\%) & 71.25 & 62.5 & 77.5 & 73,75 & 88 \\
\hline
\end{tabular}

\section{Conclusions}

Learners' learning styles are observed in a variety of ways and they are used to enhance learning environment by addressing individual learner's preferences. To date, for observing learning styles, there different approaches are being applied, namely, as a questionnaire, as a plugin embedded to or as a part of an enhanced e-learning platforms, or as standalone instruments (like the current work). In this context, a central issue for this field is related to use comprehensive automated methods. 
By merging FSLSM with our pedagogical scenario and the novel web-based interactive instrument we have been able to accurately initialize students' learning styles. In our future works we will enhance the instrument by enriching its contents with audio and video contents. Furthermore, we will develop authoring systems embedded to elearning platforms. Then, data measured by the instrument can be observed to e-learning environments seamlessly.

\section{References}

[1] F. Coffield, D. Moseley, E. Hall, and K. Ecclestone, "Learning styles and pedagogy in post16 learning: A systematic and critical review," ed: Learning and Skills Research Centre London, 2004.

[2] R. M. Felder and L. K. Silverman, "Learning and teaching styles in engineering education," Engineering education, vol. 78, no. 7, pp. 674-681, 1988.

[3] N. Stash and P. De Bra, "Incorporating cognitive styles in AHA!(The adaptive hypermedia architecture)," in Proceedings of the IASTED International Conference Web-Based Education, 2004, pp. 378-383.

[4] V. Yannibelli, D. Godoy, and A. Amandi, "A genetic algorithm approach to recognise students' learning styles," Interactive Learning Environments, vol. 14, no. 1, pp. 55-78, 2006. https://doi.org/10.1080/10494820600733565

[5] P. García, A. Amandi, S. Schiaffino, and M. Campo, "Evaluating Bayesian networks' precision for detecting students' learning styles," Computers \& Education, vol. 49, no. 3, pp. 794808, 2007. https://doi.org/10.1016/j.compedu.2005.11.017

[6] B. E. Florián G, S. M. Baldiris, R. Fabregat, and A. De La Hoz Manotas, "A set of software tools to build an author assessment package on Moodle: Implementing the AEEA proposal," in 10th IEEE International Conference on Advanced Learning Technologies, ICALT 2010, Sousse, 2010, pp. 67-69.

[7] S. V. Kolekar, R. M. Pai, and M. P. MM, "Prediction of Learner's Profile based on Learning Styles in Adaptive E-learning System," International Journal of Emerging Technologies in Learning (iJET), vol. 12, no. 06, pp. 31-51, 2017. https://doi.org/10.3991/ijet.v12i06.6579

[8] P. Q. Dung and A. M. Florea, "A literature-based method to automatically detect learning styles in learning management systems," in Proceedings of the 2nd International Conference on Web Intelligence, Mining and Semantics, 2012, p. 46: ACM. https://doi.org/10.1145/225 4129.2254186

[9] X. Tsortanidou, C. Karagiannidis, and A. Koumpis, "Adaptive educational hypermedia systems based on learning styles: The case of adaptation rules," International Journal of Emerging Technologies in Learning, Article vol. 12, no. 5, pp. 150-168, 2017. https://doi.org/10.3991/ijet.v12i05.6967

[10] J. W. Keefe, "Learning style: An overview," Student learning styles: Diagnosing and prescribing programs, vol. 1, pp. 1-17, 1979.

[11] C. Jung, Psychological Types. London: Pantheon Books, 1923.

[12] D. Kolb, "Experiential learning as the science of learning and development," ed: Englewood Cliffs, NJ: Prentice Hall, 1984.

[13] R. M. Felder and E. R. Henriques, "Learning and teaching styles in foreign and second language education," Foreign language annals, vol. 28, no. 1, pp. 21-31, 1995. https://doi.org/10.1111/j.1944-9720.1995.tb00767.x 
[14] T. A. Litzinger, S. H. Lee, and J. C. Wise, "A study of the reliability and validity of the Felder-Soloman Index of Learning Styles," in Proceedings of the 2005 American Society for Education Annual Conference \& Exposition, 2005, pp. 1-16.

[15] B. A. Soloman and R. M. Felder, "Index of learning styles questionnaire," NC State University. Available online at: http://www.engr.ncsu.edu/learningstyles/ilsweb.html (last visited on 14.05. 2010), vol. 70, 2005.

\section{Authors}

Doniyorbek Qambaralievich Ahmadaliev is working toward the $\mathrm{PhD}$ degree with School of Information Science and Technology, Northeast Normal University, Jilin, China (https://orcid.org/0000-0002-4052-9940).

Chen Xiaohui is a professor in Theory of Educational Technology at the School of Information Science and Technology, Northeast Normal University, Jilin, China.

Murodjon Abduvohidov is an associate professor at the Department of Information Technology, Andijan State University, Uzbekistan.

Article submitted 12 April 2018. Resubmitted 19 June 2018. Final acceptance 20 June 2018. Final version published as submitted by the authors. 